\title{
Os limites do liberalismo: uma crítica comunitarista.
}

The limits of liberalism: a communitarian critique.

Resumo: O propósito do artigo é entrar na controvérsia entre liberais e comunitaristas no referente à concepção de justiça e sua fundamentação. Mais especificamente, o texto discute a crítica de M. Sandel ao liberalismo político de J. Rawls. Aponta vários equívocos daquele considerando os significativos esclarecimentos e reformulações por este, nos livros posteriores à publicação de Uma Teoria da Justiça. Comenta a crítica, feita por Sandel, do afastamento das questões morais, a controvérsia em torno da prioridade do justo em relação ao bem e a restrição do âmbito da razão pública.

Palavras-chave: liberalismo, justiça, comunitarismo, razão pública, pluralismo.

\begin{abstract}
This paper aims to enter into the controversy between liberals and communitarians regarding their conception of justice and their groundings. More specifically, the text discusses M. Sandel's critique of J. Rawls's liberalism. It points out several misconceptions in Sandel's work in light of the significant clarifications and reformulations done by Rawls, in the books published after $A$ Theory of Justice. The paper comments on Sandel's critique of the disregard for moral issues, on the controversy about the priority of fairness over the good, and on the restriction of public reason's scope.

Key-words: liberalism, justice, communitarianism, public reason, pluralism.
\end{abstract}

\section{Introdução}

As divergências entre liberais e comunitaristas no que diz respeito ao tema da justiça ocupam o debate da Filosofia Política nas últimas décadas. A prioridade do justo em relação às concepções comunitárias do bem é um dos aspectos centrais da discussão. Com pontos de partida distintos, o desafio é comum a essas duas correntes: Como fundamentar normas, sejam elas regras ou princípios?

1 * Professor titular dos Programas de Pós-Graduação em Filosofia e em Direito da PUCRS. Porto Alegre, RS, Brasil. E-mail: <weberth@pucrs.br>. 
Uma das mais influentes teorias da justiça desenvolvidas na segunda metade do século XX é indiscutivelmente a da justiça como equidade de J. Rawls. Objetivando ser uma alternativa ao utilitarismo, amplamente difundido até então, a teoria rawlsiana inova em vários aspectos: a ideia de um construtivismo político, o consenso sobreposto, a prioridade do justo em relação às ideias do bem e a ideia de razão pública, merecem destaque. Sua teoria foi objeto de muitos comentários e críticas, provocando inúmeras reformulações. Essas observações, em geral, vêm do lado dos comunitaristas, entre os quais cabe destacar: M. Sandel, A. MacIntyre, C. Taylor e J. Habermas.

O propósito é discutir e avaliar a crítica de M. Sandel ao liberalismo político de Rawls, principalmente, a partir do livro $O$ liberalismo e os limites da justiça².

Como o núcleo duro dessa crítica gira em torno da prioridade do justo em relação ao bem, tese defendida por Rawls, o propósito é colocar em diálogo aquelas correntes. Os comunitaristas sustentam haver uma concepção de bem subjacente às doutrinas liberais e situam o justo a partir da ideia de contexto. Os liberais, por sua vez, são avessos ao contexto e defendem a neutralidade ética do direito. Entrar nesse debate significa acompanhar o que há de mais atual nas recentes discussões da Filosofia Política.

No referido livro, depois da reconstrução das principais teses de Rawls que envolvem o liberalismo político, Sandel o avalia através de "três objeções": o afastamento das questões morais importantes; o fato do pluralismo razoável, também envolvendo concepções de justiça; a excessiva restrição do âmbito da razão pública. Além disso, no livroJustiça: o que é fazer a coisa certa, o autor discute outros temas diretamente ligados ao liberalismo político, tais como o dos incentivos e o do esforço. Uma avaliação dos equívocos e acertos de Sandel precisa considerar as reformulações de Rawls em O Liberalismo Político e em Justiça como Equidade: uma reformulação. É o que se propõe o presente artigo: avaliar a crítica de Sandel a partir dessas reformulações.

\footnotetext{
${ }^{2}$ Uma oportuna e interessante avaliação da crítica de Sandel a Rawls, feita nesse livro, é elaborada por R. Forst no primeiro capítulo de Contextos da Justiça. Trata-se da "crítica do eu desvinculado". Segundo Forst, nessa crítica Sandel não faz uma adequada distinção entre pessoa ética e pessoa do direito, em Rawls (cf. Forst, 2010, p. 17). O presente artigo não examina a crítica de Sandel sob esse aspecto.
} 


\section{Valores políticos e doutrinas morais abrangentes}

Uma das características centrais da concepção política de justiça de Rawls é a sua independência de doutrinas morais abrangentes. ${ }^{3}$ Essa posição é motivada pela possibilidade e necessidade de um acordo sobre a concepção de justiça, apta para orientar as principais instituições políticas e sociais, principalmente, a constituição política. A restrição ao domínio do político é a condição para tal acordo. As doutrinas morais abrangentes, por sua vez, podem endossar os princípios de justiça e o farão para torná-los estáveis, mas estes não podem derivar daquelas. A concepção política de justiça tem, pois, a característica de ser autossustentada. As diferentes concepções de vida boa, próprias das doutrinas abrangentes, dificultam enormemente a possiblidade de se atingir o "propósito político" do liberalismo político, ou seja: "assegurar a cooperação social com base no respeito mútuo" (SANDEL, 2005, p. 258).

Seria esse objetivo tão importante a ponto de superar outros interesses originários de doutrinas morais? Para Sandel, muitas "exigências e reivindicações" emergem dessas doutrinas e, por isso, não é "razoável”, para "efeitos políticos", excluí-los ou simplesmente deixá-los de lado (SANDEL, 2005, p. 257), até porque algumas delas podem ser verdadeiras.

Não há dúvida de que, nas sociedades democráticas, diferentes concepções de "vida boa" são apresentadas e defendidas. Rawls reconhece isso e considera fundamental que elas endossem os princípios da justiça como equidade. Para Sandel, todavia, a questão é saber até que ponto essas doutrinas morais são ou não capazes de "superar os valores políticos" (SANDEL, 2005, p. 259). Sustentar que se trata de domínios diferentes os valores políticos, referindo-se aos elementos constitucionais essenciais e às questões de justiça básica, por um lado, e as doutrinas morais e religiosas, reportando-se à vida privada ou às "associações voluntárias", por outro - não avança na discussão, pois nesse caso nenhum conflito surgiria, segundo Sandel. Logo, não faria sentido dizer, como fez Rawls, que os valores políticos haveriam de se sobrepor aos valores éticos, religiosos ou diferentes concepções do bem. Se são âmbitos distintos, não

\footnotetext{
${ }^{3}$ Esse assunto perpassa praticamente toda a obra O Liberalismo Político de Rawls. Pode-se ver, principalmente, o primeiro capítulo.
} 
teríamos conflitos. Ocorre, no entanto, que Sandel não justifica sua afirmação da ausência desses conflitos. Exemplos mostram que eles acontecem, até mesmo entre os valores políticos. Isso indica o fato de Rawls ter estabelecido a prioridade do primeiro princípio em relação ao segundo.

Para demonstrar que a prioridade do justo sobre o bem não pode ser sustentada, Sandel, a título de exemplo, promove um debate sobre o aborto e a escravidão. Alega que um posicionamento contra ou a favor em ambos os casos não pode afastar argumentos morais importantes. Essa exclusão dependeria do fato de se saber qual das doutrinas morais é verdadeira.

Ora, o tema do aborto não é objeto de debate no nível dos princípios, mas assunto a ser enfrentado no estágio legislativo. Já o problema da escravidão pode ser resolvido a partir do primeiro princípio de justiça de Rawls e sem apelo aos valores morais e religiosos. Estes, por certo, estarão em consonância com o primeiro princípio. O recurso aos direitos fundamentais é suficiente para condenar quaisquer formas de escravidão. As doutrinas morais abrangentes poderão endossar a defesa desses direitos, por diferentes razões, mas não é preciso recorrer a elas para condenar a escravidão.

O acordo político em torno dos princípios, feito sob o véu da ignorância, diz respeito aos elementos constitucionais essenciais. Os assuntos controversos não entram na agenda política. Por isso, são decididos em outro estágio, onde o véu da ignorância é parcialmente suspenso. Nesse estágio, os cidadãos argumentarão a partir de suas concepções de bem. Aliás, também endossarão os princípios de justiça a partir dessas concepções. O limite delas, no entanto, são os princípios de justiça política. A solução de possíveis conflitos precisa estabelecer prioridades, mas deve fazê-lo a partir de um critério objetivo e comum.

A não-dependência de doutrinas morais abrangentes por parte dos princípios de justiça afeta, pois, somente a estes. A crítica sobre o fato do debate em torno do aborto não poder ser moralmente neutro, isto é, não poder desconhecer razões morais e religiosas, não considera suficientemente os quatro estágios da aplicação dos princípios de Rawls. ${ }^{4}$

\footnotetext{
4 Trata-se dos estágios da posição original, do constitucional, do legislativo e do judicial. No assunto em pauta, cabe registrar que o primeiro se ocupa da construção dos princípios de justiça; o segundo
} 
Que uma argumentação a favor do aborto não possa ser neutra no referente às controvérsias morais e religiosas dá a entender que não se pode fazer um debate sobre o assunto fora dessas controvérsias. Ser contra o aborto não significa necessariamente valer-se de um argumento moral ou religioso. A hipótese de que uma doutrina moral abrangente possa estar correta no que concerne ao fato do início da vida dar-se no momento da concepção e que, por conseguinte, o argumento do liberalismo político em torno da prioridade do justo caia por terra, esbarra num problema: como saber se uma doutrina moral está correta?

Sandel supõe que a posição da Igreja Católica sobre o início da vida esteja certa. Isso, por si só, derrubaria a tese da prioridade do justo. Mas não sabemos qual é a posição correta. Quem tem competência para definir essa questão? A ciência ou a religião? Quando efetivamente começa a vida para a biologia? Trata-se de uma questão científica, moral ou religiosa? Para as doutrinas morais e religiosas a sua posição é a correta e certamente o é. Mas como compartilhar essas diferentes teses? Do ponto de vista político deveria haver um acordo. Se não houver, decida-se no voto. É claro que isso poderá contrariar a posição de alguma doutrina religiosa.

A questão é saber que tipo de argumentos são mais plausíveis neste debate e passíveis de um acordo. Estar o início da vida vinculada à concepção pode não ser uma questão a ser resolvida por alguma doutrina moral ou religiosa. Essa é uma tese defensável. Mesmo que a questão do início da vida, referida inúmeras vezes por Sandel, estivesse resolvida, a controvérsia em torno do aborto continuaria, independente das doutrinas abrangentes. Por isso, a questão acaba por ser decidida no estágio legislativo.

De qualquer sorte, pode-se sustentar que a definição sobre o início da vida não cabe a alguma doutrina moral ou religiosa. É, antes, uma questão da ciência biológica. É claro que uma doutrina moral e religiosa pode e deve posicionar-se sobre esse tema. Pode sustentar, por exemplo, o princípio da santidade da vida e de sua origem divina. No entanto, essa sempre será a posição de uma doutrina abrangente. Mas como atingir um acordo sobre tais argumentos? Diferentes doutrinas sustentarão 
diferentes posições. A restrição ao domínio do político pretende atender à exigência da justificação pública para os valores políticos. É claro que isso não resolve o problema moral ou religioso. Essas doutrinas poderão continuar defendendo seus princípios e continuar considerando suas posições como verdadeiras e corretas.

Para Rawls, os argumentos em torno dos valores políticos seriam mais razoáveis porque são "compartilháveis" (shared) (RAWLS, 2005, p. 176), coisa que os argumentos éticos e religiosos não necessariamente são. Aqueles são passíveis de justificação pública, estes não. Ocorre que Sandel não admite que argumentos a favor do aborto possam ser neutros em relação às doutrinas religiosas e morais. Por que não? Se a questão do início da vida não é primeiramente uma questão moral ou religiosa, uma argumentação neutra em relação a ela deve ser possível. Contra Sandel dois aspectos precisam ser salientados: a) que o aborto não é tema de um princípio de justiça, mas de legislação ordinária; b) no estágio legislativo argumentos morais têm espaço, uma vez que podem e devem endossar os valores políticos, e o fazem a partir de suas concepções de bem. Quando elementos constitucionais não são objeto de discussão, os cidadãos, e mesmo os legisladores (terceiro estágio), podem tomar decisões de acordo com suas visões mais abrangentes (cf. 2005, p. 235). Mas sempre vai predominar o critério da maioria, como recurso procedimental. Leis injustas, no entanto, podem ser instituídas. Às vezes, temos o dever de obedecê-las.

O mesmo questionamento, referente à prioridade do justo sobre o bem, é desenvolvido no debate sobre a escravidão. Excluir "questões morais controversas" com o intuito de alcançar um "acordo político" é a estratégia de Rawls, na avaliação de Sandel (Sandel, 2005, p. 261). Este, no entanto, questiona a legitimidade daquela. Não é possível posicionar-se contra a escravidão, assim como em relação ao aborto, sem recorrer a argumentos morais de doutrinas abrangentes ou defender uma neutralidade em relação a eles.

Em primeiro lugar, é preciso que se diga que o recurso aos princípios de justiça, por si só, bastaria para condenar a escravidão. Ela viola os direitos e liberdades fundamentais e, portanto, a dignidade humana. A concepção política de justiça não depende de doutrinas abrangentes para essa justificação. Em segundo lugar, essas doutrinas poderão endossar os princípios e valores políticos a partir de suas 
concepções de bem. Com isso, não seria preciso excluir os argumentos morais e religiosos, com o intuito de obter um acordo político. Em terceiro lugar, questões controversas não podem ser introduzidas na agenda política; devem ser resolvidas no estágio legislativo. Se as questões controversas podem ser resolvidas no nível dos princípios, por que recorrer às doutrinas morais abrangentes? Não se trata de afastá-las, mas de dispensar o recurso a elas, dada a dificuldade de um acordo, uma vez que está em jogo uma concepção política e pública de justiça. Logo, uma argumentação contra o aborto pode ser moralmente neutra, isto é, imparcial, do ponto de vista da justificação. ${ }^{5}$

\section{A prioridade do justo e o pluralismo}

Rawls parte de um fato: o fato do pluralismo razoável. Uma sociedade democrática convive com distintas doutrinas morais, religiosas e filosóficas abrangentes e, por vezes, incompatíveis, mas razoáveis. Diante desse pluralismo, impõe-se a prioridade do justo. A grande dificuldade refere-se à possibilidade de construir uma concepção de justiça a partir disso. Uma restrição em relação a uma concepção política de justiça foi a solução encontrada. De acordo com Sandel, para o liberalismo político esse pluralismo diz respeito tão somente às concepções de bem e, por isso, atribui a prioridade ao justo. Essa "assimetria", no entanto, para Sandel, tem um pressuposto sem o qual ela não se sustenta. O liberalismo tem de pressupor que não há um pluralismo razoável acerca da justiça.

O liberalismo político tem de pressupor não só que o exercício da razão humana em condições de liberdade produzirá desacordos acerca da vida boa, mas também que o exercício da razão humana em condições de liberdade não produzirá desacordos acerca da justiça. (SANDEL, 2005, p. 266)

Ora, sustenta Sandel, tão fato quanto o pluralismo razoável de doutrinas morais abrangentes é o fato do pluralismo razoável em torno da ideia de justiça. "As sociedades democráticas", afirma, "estão repletas de desacordos acerca da justiça” (SANDEL, 2005, p. 266). Ele fornece como exemplos os debates sobre a distribuição do rendimento e da equidade de

\footnotetext{
${ }^{5}$ Sobre o tema da neutralidade no sentido aqui tratado, ver Forst, R. Contextos da Justiça, p. 63.
} 
impostos, os cuidados com a saúde, os direitos dos homossexuais, a liberdade de expressão, etc. Os votos discordantes dos juízes da Suprema Corte, em situações que envolvem a liberdade religiosa, a liberdade de expressão, etc, é outro exemplo. Os debates em torno desses temas indicam o pluralismo razoável acerca da justiça. Ora, se houver um pluralismo tanto em relação à justiça quanto em relação às doutrinas morais e abrangentes, qual é a diferença no referente aos dois tipos de pluralismos? A dificuldade para um acordo não se aplica a ambos? Por que então estabelecer a prioridade do justo sobre o bem?

Os defensores do liberalismo político, na apreciação de Sandel, poderiam responder dizendo que as divergências sobre a justiça não se referem ao que os princípios devem ser e, sim, à sua aplicação. Haveria concordância, por exemplo, quanto à liberdade de expressão constar da lista dos direitos fundamentais, mas discordância quanto ao entendimento desse direito em alguns casos concretos, como por exemplo, se a liberdade de expressão deve ou não proteger toda e qualquer publicidade comercial. Sandel, apesar dessa resposta, continua sustentando que as divergências dizem respeito aos princípios e não só a sua aplicação. Ele dá como exemplo as divergências entre liberais libertários e liberais igualitários, no que diz respeito ao princípio da diferença. Para os igualitários (Rawls é um deles) qualquer incentivo concedido aos mais capazes deve melhorar a vida dos menos favorecidos. Somente assim se justificam. As desigualdades econômicas e sociais somente são justas se melhorarem a situação dos menos favorecidos. Os libertários sequer aceitam esse princípio. Cobrar impostos dos ricos para ajudar aos pobres é injusto. Tais contribuições deveriam ser facultativas.

Essas divergências mostram um "pluralismo razoável acerca da justiça” (SANDEL, 2005, p. 269). Elas indicam discordância com relação à própria compreensão do princípio da justiça distributiva e não só em relação a sua aplicação. O debate indica divergências em relação ao que esse princípio deveria ser. Diante disso, para Sandel, mais uma vez, a prioridade do justo em relação ao bem não se sustenta.

Ora, é um equívoco achar que não há um pluralismo em relação as concepções de justiça em Rawls, tanto é que ele considera a sua teoria da justiça como equidade uma alternativa ao utilitarismo, mesmo o considerando uma doutrina moral abrangente. Em Justiça como equidade: uma reformulação, fala em escolha diante de um menu, isto é, um conjunto 
de concepções de justiça encontráveis na tradição da filosofia política. Isso indica que a posição original é um "procedimento de seleção" (RAWLS, 2003, p. 117). Mesmo em Uma Teoria da Justiça são citadas outras concepções de justiça (sob o título "The presentation of alternatives") ao lado da justiça como equidade (cf. 1997, p. 122).

A questão fundamental para a justiça política é saber "qual é a concepção de justiça mais apropriada para especificar os termos da cooperação social entre cidadãos considerados livres e iguais, membros normais e plenamente cooperativos da sociedade, ao longo de toda vida" (RAWLS, 2005, p. 20). Existem muitas teorias concorrendo para isso. Todas razoáveis. É preciso escolher uma dentro do menu. Para Rawls, as partes, na posição original, escolheriam a justiça como equidade como a mais razoável e que mereceria o endosso das doutrinas morais abrangentes. É um equívoco, portanto, considerar que "não existe qualquer fato de pluralismo razoável” acerca da justiça (SANDEL, 2005, p. 269). Além do mais, Rawls nunca afirmou que as outras teorias de justiça não seriam razoáveis. Há uma diversidade de concepções de justiça em concorrência na nossa tradição político-filosófica, embora umas possam ser mais razoáveis do que outras. O fato da posição original ser um procedimento de seleção é a maior prova disso.

Oportuna questão é sugerida por Sandel: se alguns princípios de justiça são mais razoáveis do que outros, o mesmo não poderia ser dito das doutrinas morais abrangentes? E algumas dessas doutrinas não poderiam ser mais razoáveis do que as concepções de justiça?

O núcleo central dessas questões passa pela discussão sobre a própria possibilidade do liberalismo. Ou seja, admitindo o pluralismo razoável de doutrinas morais abrangentes e mesmo de concepções de justiça, por que os valores políticos se impõem sobre os demais? O problema não é só de razoabilidade, mas do grau de importância. É disso que Rawls deve convencer-nos.

A resposta encontramos em $O$ Liberalismo Político, sobretudo na conferência IV, que trata do "consenso sobreposto". Os "valores do domínio especial do político" superam quaisquer outros valores porque são efetivamente "muito importantes", ou seja, referem-se à estrutura básica da sociedade e "especificam os termos essenciais da cooperação política e social” (RAWLS, 2005, p.139). Tais valores constituem elementos constitucionais essenciais. Rawls dá como exemplo desses valores, 
expressos pelos princípios de justiça, "os valores da igual liberdade política e civil; igualdade equitativa de oportunidades; os valores da reciprocidade econômica; as bases sociais do respeito mútuo entre os cidadãos" (RAWLS, 2005, p. 139). Esses valores são realmente essenciais para um acordo político, pois, são condições para o pleno exercício da cidadania. Em caso de conflito desses valores com os das doutrinas morais abrangentes aqueles se impõem pela sua importância para uma sociedade cooperativa.

Não há dúvida de que existe um pluralismo razoável em torno da justiça. A questão é avaliar qual ou quais dos princípios têm mais chance de ser objeto de um acordo para orientar nossas principais instituições sociais e políticas. A questão é saber o que realmente é importante para o domínio do político. É fundamental que, para sua estabilidade, os valores desse domínio sejam endossáveis pelas doutrinas abrangentes.

A controvérsia em torno do "estatuto moral da homossexualidade", sugerida por Sandel, não é um bom exemplo. Esse assunto é objeto de discussão e ponderação no estágio legislativo e não na construção dos princípios da posição original. Não é, portanto, elemento constitucional essencial. É uma questão de lei e não de princípio. No legislativo os argumentos morais têm força e podem ser adotados pelos cidadãos. O véu da ignorância afeta a construção dos princípios, mas não a elaboração das leis, ou pelo menos não em parte. Não há dúvida de que nessa elaboração, os cidadãos vão argumentar a partir de seus interesses e concepções de bem, isto é, a partir de uma razão não-pública. O critério aqui é o voto da maioria.

Assim, para mostrar o que deve e o que não deve entrar no debate político, é um equívoco comparar as divergências em relação ao princípio da diferença com as divergências em relação ao estatuto moral da homossexualidade. Significa confundir princípios com regras, ${ }^{6}$ elementos constitucionais essenciais com assuntos de legislação ordinária. É preciso entender que o princípio da diferença é mais razoável do que a opção indicada pelos libertários. Divergências em torno dos princípios de justiça sempre vão ocorrer. Por isso a necessidade de escolhas. Perelman diria que sempre haverá "um elemento arbitrário" nessas escolhas. É por isso que elas devem ser justificadas perante o "auditório universal”, isto é, perante "mentes razoáveis", obedecendo a coerência e a regularidade (Perelman,

\footnotetext{
${ }^{6}$ Sobre a distinção entre princípios e regras, ver Dworkin, Levando os direitos a sério, p. 35.
} 
2002, p. 67 e 94). Essa arbitrariedade é própria de um "sistema normativo" (Perelman, 2002, p. 59).

Sandel admite que exista um pluralismo acerca da justiça distributiva em Rawls, mas que "não existe qualquer fato de pluralismo razoável” (SANDEL, 2005, p. 269). Em nota do livro O liberalismo e os limites da justiça, ele reconhece que Rawls não diz isso de "forma explícita”, mas entende que isso é necessário para que a tese do fato do pluralismo razoável faça sentido. No entanto, pode-se dizer, com toda segurança, que Rawls não afirma a não-existência do pluralismo em questões de justiça, nem explícita e nem implicitamente. Ao contrário, a necessidade de escolha diante de um conjunto de concepções de justiça encontráveis na tradição da Filosofia Política (menu) é a prova incontestável desse pluralismo. A posição original é um procedimento de seleção.

\section{A excessiva restrição do âmbito da razão pública liberal}

A tese da prioridade do justo sobre o bem perpassa todo o liberalismo político de Rawls. A independência dos princípios de justiça para com as doutrinas morais abrangentes se impõe como condição de possibilidade de um acordo. A razão pública diz respeito somente ao objeto desse acordo, ou seja, aos "elementos constitucionais essenciais e questões de justiça básica” (Rawls, 2005, p. 214). Isso significa que muitos aspectos ficam de fora da "argumentação pública no fórum público" (2005, p. 215). É o que Rawls chama de "razões não-públicas” e dá como exemplo vários tipos de associações, tais como as igrejas, universidades e as sociedades científicas. Sua argumentação é pública em relação a seus membros, mas não-pública em relação aos cidadãos em geral. A razão pública diz respeito ao "bem do público"; é a razão dos cidadãos enquanto "corpo coletivo" (colletive body), na medida em que promulgam leis e emendam sua Constituição (RAWLS, 2005, p. 213 e p. 214). Mas existem questões políticas que não são objeto da razão pública, uma vez que não são elementos constitucionais essenciais. Exemplo disso são as leis que regulam a propriedade. $\mathrm{O}$ direito de herança, por exemplo, não é elemento constitucional essencial, embora seja uma questão política a ser resolvida (decidida) no estágio legislativo. 
Mas quais são os elementos constitucionais essenciais e qual é propriamente o conteúdo da razão pública? Em O Liberalismo Político, Rawls destaca “dois tipos” de elementos essenciais para os quais o acordo se faz necessário: o primeiro diz respeito aos "princípios fundamentais que especificam a estrutura geral do Estado e do processo político: as prerrogativas do legislativo, do executivo e do judiciário; o alcance da regra da maioria". O segundo refere-se aos "direitos e liberdades fundamentais e iguais de cidadania”, tais como o direito ao voto, a liberdade de consciência, etc. (RAWLS, 2005, p. 227). Estes elementos constituem o núcleo central da concepção política de justiça e, pois, o conteúdo da razão pública que, segundo Rawls, apresenta um “caráter liberal”. Isso significa dizer que além da especificação dos referidos direitos e liberdades fundamentais, atribui-se uma prioridade a eles, principalmente em relação às distintas concepções do bem. A ênfase está, pois, no acordo em torno de valores políticos. Segundo Rawls, esses elementos essenciais "são justificáveis perante todos os cidadãos” (RAWLS, 2005, p. 224), coisa que não ocorre com os valores morais e religiosos.

É fundamental destacar que é somente na discussão e justificação desses elementos essenciais que não se pode recorrer aos argumentos de doutrinas morais e abrangentes. Essa é a restrição que a razão pública impõe.

Sandel, como visto, não só questiona a prioridade do justo como apresenta uma séria dificuldade inerente aos limites impostos pela "razão pública liberal”. A "vida política”, afirma o autor, "deixa pouco espaço para o tipo de deliberação pública necessária para que se teste a plausibilidade de teorias morais abrangentes alternativas" (SANDEL, 2005, p. 175). Embora defenda o direito de liberdade de expressão, o "liberalismo político limita rigorosamente os tipos de argumentos que constituem contribuições legítimas para o debate político, especialmente para o debate acerca dos elementos constitucionais essenciais e das questões de justiça básica” (SANDEL, 2005, p. 275).

É preciso salientar, como Sandel reconhece, que os limites da razão pública dizem respeito aos elementos constitucionais essenciais e não afetam outros valores. Sequer incluem todas as questões políticas e muito menos se "aplicam a nossas deliberações e reflexões pessoais" sobre essas questões (RAWLS, 2005, p. 215). É que muitos desses temas não constituem problemas essenciais. Ao dizer, no entanto, que os cidadãos 
não devem introduzir suas convicções religiosas e morais no debate de "questões de justiça”, pois este é o âmbito da razão pública, o autor acaba dando exemplos e refere assuntos que não constituem elementos constitucionais essenciais. Logo, não são afetados pelos seus limites. Ele volta a se referir os casos do aborto e o dos direitos dos homossexuais. As restrições impostas pela razão pública impediriam que os cidadãos argumentassem de forma contrária a esses temas a partir de suas convicções morais e religiosas.

Ora, a adoção de uma lei a favor ou contrária ao aborto é assunto do estágio legislativo e não objeto de acordo na posição original. Não é elemento constitucional essencial. É objeto de lei e não de princípio. Os "partidários" da igreja católica, portanto, na medida em que também são cidadãos, podem não só discutir o assunto internamente, nos seus templos, mas também no "parlamento estatal". Se o aborto é objeto de lei, e o próprio Sandel afirma isso, as igrejas podem levar seus argumentos para a "arena política", neste caso o estágio legislativo. É somente no debate sobre as "questões políticas mais fundamentais" que elas devem respeitar os limites da razão pública (2005, p. 226). Ora, o aborto não se enquadra nessas questões, ainda que possa ser considerado uma questão de saúde pública. Como referido, existem muitas outras questões públicas que não são objeto da razão pública. Além do mais, questões controversas, como é o caso do aborto, não entram na agenda política.

O mesmo argumento vale para os defensores dos direitos dos homossexuais. Nesses casos, é um engano pensar que as conviç̧ões e argumentos morais e religiosos não possam ter lugar no debate público. Os princípios de justiça é que não podem ser construídos em função desses argumentos. O acordo em torno de elementos constitucionais essenciais visa obter o endosso das doutrinas morais abrangentes, exatamente, a partir de suas convicções e valores. Este é o princípio da legitimidade dos princípios políticos de justiça. Mas esse endosso pode ser feito por diferentes razões.

Quando fala dos direitos dos homossexuais e do aborto, Sandel fala em elaboração de leis. Ora, leis não são princípios e os elementos constitucionais essenciais, objeto da razão pública, referem-se aos princípios e não às leis. Rawls é claro ao sustentar que o apelo às doutrinas morais e religiosas só não pode ser feito quando estão em debate elementos constitucionais essenciais. Em O Liberalismo Político lemos: "ao 
discutir sobre elementos constitucionais essenciais e sobre questões de justiça básica não devemos apelar para doutrinas religiosas e filosóficas abrangentes" (RAWLS, 2005, p. 225). Mas isso não vale para a elaboração de leis no estágio legislativo. Neste estágio já estamos pensando em determinada sociedade. É perfeitamente razoável votar a favor de uma lei contrária ao aborto com base em argumentos morais e religiosos. No entanto, as doutrinas morais e abrangentes e os seus valores não são compartilháveis e, por isso, não são e nem precisam ser objeto da razão pública. Rawls afirma claramente que "os cidadãos e os legisladores podem votar de acordo com suas visões mais abrangentes quando os elementos constitucionais essenciais e a justiça básica não estiverem em jogo (at stake); não precisam justificar, por meio da razão pública, porque votam desta ou daquela maneira" (2005, p. 235). Por que? Simplesmente porque o assunto em pauta não é elemento constitucional essencial. Logo, não exige uma "base pública de justificação" (RAWLS, 2005, p. 225).

Contudo, controvérsias poderão surgir em torno do fato do aborto enquadrar-se ou não nos elementos constitucionais essenciais. Essa é uma dificuldade da razão pública que o próprio Rawls reconhece, quando afirma: "a razão pública muitas vezes admite mais de uma resposta razoável a uma questão específica, isto porque existem muitos valores políticos e muitas formas de caracterizá-los” (2005, p. 240). Ao referir-se à formulação de uma lei contra o aborto, Sandel está retirando esse assunto do referido status. É, no entanto, no julgamento da constitucionalidade das leis que os juízes da Suprema Corte, como guardiães da Constituição, não podem invocar valores morais e religiosos. Podem invocar valores endossáveis pelos “cidadãos razoáveis e racionais", que são os valores políticos.

Além disso, Rawls admite que existem argumentos políticos excluídos pela razão pública. Quais? Os que não são elementos constitucionais essenciais como, por exemplo, a legislação fiscal. É assunto de outro estágio. As questões referentes ao aborto, os direitos dos homossexuais e do abolicionismo são citados por Sandel como exemplos para os quais não podem ser usados argumentos morais e religiosos no debate político. A "razão pública liberal” requer que sejam colocadas de lado quando se tornarem decisões referentes à justiça (Sandel, 2005, p. 280). Isto representa, para Sandel, um "custo moral estrito", ou indica “custos morais da razão pública liberal” (p. 280). 
Seria excessiva essa restrição da razão pública? Trata-se de um problema prático: a possibilidade de se chegar a um acordo sobre o que é realmente essencial para a vida política. Alguém poderia sustentar que no debate sobre uma lei contrária ao aborto e sobre o direito dos homossexuais podemos encontrar argumentos suficientes nos próprios princípios de justiça, sem necessidade de recurso às doutrinas morais. $\mathrm{O}$ aborto violaria a dignidade do feto e os homossexuais devem ter direitos iguais reconhecidos. Não se trata, portanto, de neutralidade em face dos argumentos morais e abrangentes, mas de dispensar o recurso a eles, tendo em vista a dificuldade de um acordo e considerando a suficiência do recurso aos elementos constitucionais essenciais. Nesse caso, o debate respeitaria os limites da razão pública. Os princípios, no entanto, necessitam de interpretação, uma vez que não se referem, e nem precisam se referir, claramente a esses temas. Limites se impõem.

\section{O problema dos incentivos e da valorização do esforço}

Outros temas de intenso debate e objeto de muita controvérsia no referente ao liberalismo político de Rawls são o dos incentivos e o do mérito pelo esforço. Sandel os discute apresentando algumas objeções ${ }^{7}$. O alvo da crítica aqui é o princípio da diferença. Referindo-se aos incentivos ${ }^{8}$, a pergunta de Sandel é plausível: "se os talentosos só puderem se beneficiar de suas aptidões quando eles ajudarem os menos favorecidos, o que acontecerá se eles resolverem trabalhar menos ou não desenvolverem suas habilidades? " (SANDEL, 2014, p; 195). Ou seja, se a ajuda aos menos favorecidos é condição para se beneficiar das próprias aptidões, por que deverão os talentosos trabalhar mais? Por que M. Jordan haveria de se esforçar tanto, já que com isso terá um salário maior e terá que pagar mais impostos?

De fato, o princípio da diferença permite desigualdades de renda, concessões de incentivos e até privilégios, desde que isso de algum modo beneficie os menos favorecidos. Não é justo tratar os diferentes de forma igual. Desigualdades são justificáveis e diferenças salariais, a título de incentivos, são perfeitamente justas, desde que isso reverta em benefícios

\footnotetext{
${ }^{7}$ Estes assuntos são mais especificamente examinados em Justiça: o que é fazer a coisa certa.

${ }^{8}$ Sobre o tema dos incentivos, ver A. SEN, A Ideia da Justiça, 2011, p. 91.
} 
para os menos privilegiados. A objeção, no entanto, faz sentido: por que irão os talentosos trabalhar mais ou escolher profissões mais atraentes financeiramente se com isso deverão pagar mais impostos e ajudar os menos favorecidos? Não se sentirão penalizados? O que deveria motivar os mais talentosos a investirem nas suas habilidades?

Rawls, no entanto, tem um forte contra-argumento: as capacidades naturais não são merecidas. Logo, uma sociedade justa deve organizar os princípios da justiça distributiva de sorte a favorecer os menos capacitados. Afirma o autor em Uma Teoria da Justiça: "desigualdades imerecidas (undeserved inequalities) exigem reparação; e como desigualdades de nascimento e de dotes naturais são imerecidas, devem elas ser de alguma forma compensadas” (RAWLS, 1997, p. 100). Esta é a alternativa que Rawls oferece ao utilitarismo. Não é o maior bem para o maior número de pessoas que importa, mas a equidade entre todos. Numa sociedade justa, com a concessão de benefícios aos mais habilidosos, as minorias e os menos dotados devem ser valorizados e beneficiados. $\mathrm{O}$ princípio da diferença incentiva os mais aptos valorizando as minorias.

Outra "desafiadora objeção" à concepção de justiça de Rawls e ligada ao tema dos incentivos diz respeito ao problema do esforço. É sabido que o autor não aceita a teoria meritocrática de justiça. Sandel resume a justificativa de Rawls para tal tese afirmando que para o filósofo da equidade "os talentos naturais não são méritos de quem os possui" (SANDEL, 2014, p. 196). Rawls refere-se a esse assunto já em Uma Teoria da Justiça. Não há merecimento dos dotes naturais, uma vez que isso depende da família em que nascemos e do tipo de educação que recebemos. "Não merecemos nosso lugar na distribuição de aptidões inatas, assim como não merecemos nosso lugar inicial de partida (initial starting place) na sociedade" (RAWLS, 1997, p. 104). Certamente os mais habilidosos têm direito aos seus talentos naturais. Isso é assegurado pelo primeiro princípio da justiça. É, pois, justo o que é obtido dentro das regras do "sistema equitativo de cooperação social" (RAWLS, 1997, p. 104). O direito às expectativas legítimas está vinculado às regras estabelecidas de acordo com os princípios de justiça. Para Rawls, o problema não é o da justiça ou injustiça da "distribuição natural" dessas capacidades inatas, mas a maneira como as instituições lidam com isso. Essa maneira pode ser justa ou injusta. 
No entanto, deve-se indagar se é razoável uma teoria da justiça segundo a qual não merecemos que nosso esforço seja recompensado. $\mathrm{O}$ esforço decorrente das qualidades naturais certamente é meritório. Repudiar o mérito moral sob alegação de que a sociedade valoriza mais certas qualidades em certas épocas e que, por isso, o sucesso é resultado da boa sorte, apenas em parte é aceitável. Escolhas mais ou menos inteligentes são feitas pelos indivíduos e muito esforço é dispensado na conquista dos objetivos previstos. É claro que não é apenas o esforço que concede mérito moral. Se assim fosse, ele seria a base da renda e riqueza. Nem os meritocratas concordariam com isso. Um trabalhador fisicamente fraco, dependendo da atividade, deverá esforçar-se muito mais do que um trabalhador forte, para obtenção de um determinado resultado. Nem por isso receberá remuneração melhor. Mas quando o esforço resulta em efetiva contribuição para a melhoria das condições de vida de uma sociedade, ele deve ser recompensado. Contra Rawls poder-se-ia dizer que a justiça distributiva deveria de alguma forma premiar o mérito moral.

Mais especificamente, o que dizer das grandes diferenças salariais. Pode-se sustentar que são justas? Considerando o segundo princípio de justiça, o princípio da diferença, as diferenças são justas na medida em que fizerem parte de uma estrutura social que prevê uma taxação na forma de impostos que venha trazer benefícios aos menos favorecidos. Além disso, existem elementos contingentes que podem determinar o maior ou menor sucesso profissional de alguém e do qual pode resultar um rendimento maior ou menor. Isso depende do que é mais valorizado. Em certas sociedades o bom jogador de futebol é extremamente bem remunerado. M. Jordan nasceu num país em que o basquete é o esporte preferido. Mas isso é contingente, e não apenas mérito moral.

\section{Referências}

RAWLS, John. A Theory of Justice. Cambridge: Harward University Press, 1997. . Political Liberalism. New York: Columbia University Press, 2005 . Justiça como Equidade: uma reformulação. São Paulo: Martins Fontes, 2003. 
340 | Veritas | Porto Alegre, v. 63, n. 1, jan-mar. 2018, p. 323-340

. Justiça: O que é fazer a coisa certa. Rio de Janeiro: Civilização Brasileira, 2014.

DWORKIN, Ronald. Levando os direitos a sério. São Paulo: Martins Fontes, 2002.

SEN, A. A Ideia da Justiça. São Paulo: Companhia das Letras, 2011.

PERELMAN, C. Ética e Direito. São Paulo: Martins Fontes, 2002.

FORST, R. Contextos da Justiça. São Paulo: Boitempo Editorial, 2010.

\section{Endereço postal}

Programa de Pós-graduação em Filosofia da PUCRS.

Avenida Ipiranga 6681, Porto Alegre, RS, Brasil

Data de recebimento: 24/10/2017

Data de aceite: 11/03/2018 